\title{
Emotional Intelligence, Problem Solving Ability, Self Efficacy, and Clinical Performance among Nursing Students: A Structural Equation Model
}

\author{
Kim, Mi Sook ${ }^{1(\mathbb{1})} \cdot$ Sohn, Sue Kyung ${ }^{2(1)}$ \\ ${ }^{1}$ Assistant Professor, Department of Nursing, Kaya University, Gimhae, Korea \\ ${ }^{2}$ Professor, Department of Nursing, Kosin University, Busan, Korea
}

\begin{abstract}
Purpose: This study aimed to construct and test the structural relationships between self efficacy and clinical performance among undergraduate nursing students. The model was based on Bandura's self efficacy theory and a review of previous studies. The hypothesized model included emotional intelligence as a personal factor, self efficacy as self efficacy beliefs, problem solving ability as a skill, and clinical performance as a performance. Methods: Data were collected from June 23 to August 11, 2014 using structured questionnaires. The study sample was 205 senior nursing students. Data were analyzed using SPSS/WIN 21.0 and AMOS 21.0 programs. Results: The hypothesized model was shown to be $x^{2}=183.186$ ( $\mathrm{dF}=118$ ), Goodness-of- Fit Index (GFI)=.91, Normed Fit Index $(\mathrm{NFI})=.91$, Comparative Fit Index $(\mathrm{CFI})=.96$, and Root Mean Squared Error of Approximation (RMSEA)=.05. Self efficacy $(\beta=.29 p=.033)$ and problem solving ability $(\beta=.42 p=.007)$ had a direct effect on the clinical performance. Furthermore, self efficacy had mediating effect on the relationship between emotional intelligence and clinical performance. Conclusion: These findings provide that when developing nursing curriculum and intervention programs, self efficacy and problem solving ability should be considered as key factors facilitating the clinical performance of nursing students. Moreover, consideration should be given to the indirect effects of emotional intelligence subscales on clinical performance via self efficacy and problem solving ability.
\end{abstract}

Key Words: Emotional intelligence; Clinical competence; Problem solving; Self efficacy

\section{INTRODUCTION}

Recently, there has been an increasing prioritization of quality of care among nurses working in the healthcare environment. For this reason, nursing education has become more focused on clinical performance in managing patients' health problems. Good clinical performance means providing appropriate nursing care to patients to improve patient outcomes [1]. Nursing students' clinical performance is a key educational outcome and results from an accumulation of theoretical knowledge and practical training [2]. It is crucial for nursing students to improve their clinical performance, which relates to the combination of knowledge, skills, and attitudes that nursing students achieve before graduating [3]

Even after completing regular nursing education cours- es, however, new nurses have been found to lack the ability to identify and solve health problems in diverse and complex situations [4]. This finding reveals a gap between the educational goals of nursing colleges and the performance required in clinical practice. Therefore, the nursing curriculum needs to focus more on performance-based learning environments [5].

Clinical performance is affected by many factors such as nursing skills, knowledge, and relationships [6]. Some recent research has indicated that emotional intelligence is a major predictor of positive clinical performance, and interest in this area has been increasing. It is reported that emotional intelligence plays a key role in the formation of successful human relationships, creates a therapeutic relationship between nurses and patients, and enhances the clinical performance of health professionals and students

Corresponding author: Sohn, Sue Kyung https://orcid.org/0000-0002-5507-5814

Department of Nursing, Kosin University, 262 Gamcheon-ro, Seo-gu, Busan 49267, Korea.

Tel: +82-51-990-2531, Fax: +82-51-990-3970, E-mail: sue@kosin.ac.kr

Received: Feb 25, 2019 / Revised: Jun 2, 2019 / Accepted: Jun 25, 2019

This is an open access article distributed under the terms of the Creative Commons Attribution Non-Commercial License (http://creativecommons.org/licenses/ by-nc/3.0), which permits unrestricted non-commercial use, distribution, and reproduction in any medium, provided the original work is properly cited. 
[7-9]. One study on the relationship between nurses' emotional intelligence and clinical performance found that others' emotional appraisal, self-emotional appraisal, and regulation of emotion significantly affected clinical performance in that order [7]. Two other studies found that emotional intelligence was an explanatory factor in clinical performance [10,11]. Yet another study found that the perception and management of others' emotions were predictors of clinical performance for occupational therapy students [12]. Meanwhile, Beauvais et al. [13] reported that, among the sub-variables of emotional intelligence, only understanding emotion had a significant relationship with performance. Because of this variety of findings, this study analyzed the interrelationships among the subscales of emotional intelligence as well as the effects of these components on clinical performance.

Problem solving ability is a nursing care provider's proficiency in quickly and accurately mediating the health problems a patient faces, even if it is the nursing care provider's first patient [14]. This is because problem solving ability can improve individual critical and creative thinking [15]; it is a core skill to identify and solve the health problems of patients in complex nursing environment [16]. Moreover, problem solving ability has been reported to be an effective factor in nursing performance [17].

Self efficacy influences individual behavior change and performance, it is an important variable that enhances self-confidence and motivation to provide appropriate nursing care in complex clinical situations [16]. Self efficacy is important for individual performance because it serves as an intermediary between individual knowledge and performance that also influences both [18-20]. Derived from social learning theory, self efficacy theory refers to an individual's belief that he or she can successfully perform the behavior needed to accomplish certain outcomes [22]. Self efficacy, which is the judgement of their capabilities to structure performance and use various skills in different situations, refers to trust in one's own ability to plan and perform the various behavioral processes required to achieve a given situational demand [18].

Previous studies have investigated only at bivariate relationships between variables related to nursing students' self efficacy and clinical performance [2,10-12]. So, it is necessary to determine the effect of the interactions among these related factors on clinical performance.

\section{Conceptual Framework}

This study's conceptual framework was based on Bandura's self efficacy theory framework $[18,21]$ as well as a related literature review (Figure 1).

According to Bandura, efficacy beliefs are important predictors of changes in human action. Efficacy beliefs are an individual's inner beliefs that they can successfully perform the behavior needed to achieve the outcome; such beliefs only affect behavior when an individual has confidence in the behavior. Thus, efficacy beliefs are important in changing an individual's behavior $[18,21]$. According to Bandura's theory, self efficacy has a mediating effect between individual knowledge and behavior [18]. Among the concepts that constitute self efficacy, the individual factors involve characteristics and perception. Characteristics refer to psychological factors such as an individual's thoughts [22,23]; perception involves how individuals assess their own and others' cognitions, emotions, and actions when responding to a given situation [22]. This relates to the concept of emotional intelligence. In clinical settings, emotional intelligence enables a person to recog-

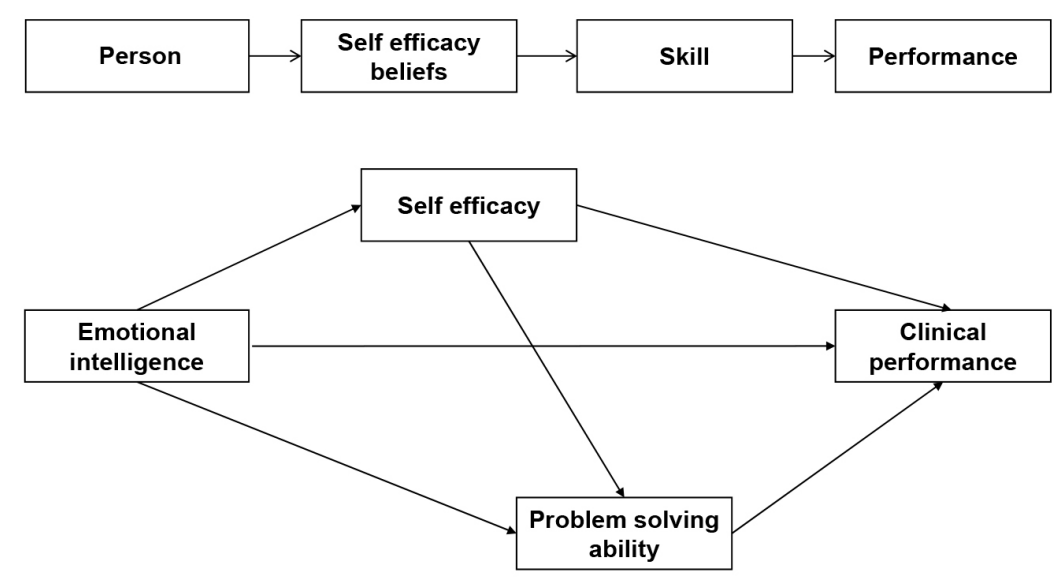

Figure 1. Conceptual framework of this study. 
nize emotions of the self and others; this helps to improve interpersonal skills and well-being in relating to clients and to other members of the medical team and to improve clinical performance through stress reduction $[12,24]$. In previous studies, high self efficacy predicted high performance in clinical practice for nursing students [25,26].

According to the literature review, individuals with high self efficacy focus on assessing problems and seeking solutions while those with low self efficacy tend to focus on their own deficiencies and thus lack the skills and attentiveness needed to handle certain tasks, which decreases problem solving ability [18]. One previous study also found that emotional intelligence, problem solving ability, and self efficacy are all factors that affect nursing students' clinical performance [27].

\section{METHODS}

\section{Design}

This study used structural equation modeling to test the goodness of fit and the hypotheses regarding causal relationships among the factors that may affect nursing students' clinical performance. The model was established based on both a literature review and on Bandura's self efficacy model $[18,21]$. There were four exogenous variables (i.e., self-emotional appraisal, others' emotional appraisal, use of emotion, regulation of emotion) and three endogenous variables (i.e., self efficacy, problem solving ability, clinical performance).

\section{Sample}

The study participants were senior baccalaureate nursing students at different schools located in Busan Metropolitan City and Gyeongnam-do Province, Korea.

\section{Instruments}

\section{1) Emotional intelligence}

This study used a Wong and Law Emotional Intelligence Scale (WLEIS) developed by Wong and Law [28] and adapted by Jung [29]. This scale includes four subscales: self-emotional appraisal (4 domains), others' emotional appraisal (4 domains), use of emotion (4 domains), and regulation of emotion (4 domains). Each domain was scored on a 7-point Likert scale, from "do not agree at all" (1) to "strongly agree" (7). Higher scores represent higher emotional intelligence. Cronbach's $\alpha$ for the four subscales of self-emotional appraisal, others' emotional ap- praisal, use of emotion, and regulation of emotion were $.89, .85, .88$, and .76 , respectively at the time of development [28], and $.83, .86, .85$, and .87 , respectively in this study (Table 1). The author received permission to use the WLEIS from the original developers via e-mail.

\section{2) Problem solving ability}

This study used problem solving ability scale developed by Lee et al. [30]. It consists of 30 items in five subscales: clarifying a problem (6 domains), seeking a solution ( 6 domains), decision making ( 6 domains), applying the solution ( 6 domains), and evaluation ( 6 domains). The questions are scored on a 5-point Likert scale, from "do not agree at all" (1) to "strongly agree" (5), with higher scores indicating higher problem solving ability. Cronbach's $\alpha$ was .93 at the time of development [30], and .93 in this study (Table 1). The author received permission to use this scale from the original developers via e-mail.

\section{3) Self efficacy}

Self efficacy was measured using a general self efficacy tool targeted at undergraduates developed by Cha [31] and modified and supplemented by Kim [32]. The scale consists of three subscales: confidence (7 items), self-regulated efficacy ( 12 items), and task difficulty ( 5 items). These questions are scored on a 5-point Likert scale, from "do not agree at all" (1) to "strongly agree" (5). Higher scores mean higher self efficacy. Cronbach's $\alpha$ was .86 at the time of development [31], and .90 in this study (Table 1). The author received permission to use this scale from the original developers via e-mail.

\section{4) Clinical performance}

Clinical performance was assessed using a clinical performance measurement tool developed by Lee et al. [33] and modified and supplemented by Yang and Park [34]. It consists of 19 items in six subscales: nursing process (4 items), nursing intervention (4 items), psychosocial nursing (3 items), teaching ( 3 items), physical examination and patient monitoring ( 2 items), and fundamental nursing ( 3 items). Each item was scored on a 5-point Likert scale, from "do not agree at all" (1) to "strongly agree" (5). A higher score indicates higher clinical performance. Cronbach's $\alpha$ was .89 at the time of development [33], and .91 in this study (Table 1). The author received permission to use this scale from the original developers via e-mail.

\section{Ethical Considerations and Procedure}

After obtaining approval from the Kosin University Ins- 
Table 1. Descriptive Statistics of Study Variables

$(N=205)$

\begin{tabular}{|c|c|c|c|c|c|c|}
\hline Variables & $\mathrm{M} \pm \mathrm{SD}$ & Skewness & Kurtosis & Cronbach's $\alpha$ & CR & AVE \\
\hline Emotional intelligence & $5.18 \pm 0.71$ & -0.08 & -0.01 & .89 & .77 & .45 \\
\hline Self-emotional appraisal & $5.44 \pm 0.88$ & -0.65 & 0.57 & .83 & & \\
\hline Others' emotional appraisal & $5.48 \pm 0.90$ & -0.41 & -0.29 & .86 & & \\
\hline Use of emotion & $5.14 \pm 0.91$ & -0.17 & -0.46 & .85 & & \\
\hline Regulation of emotion & $4.66 \pm 1.09$ & -0.10 & -0.59 & .87 & & \\
\hline Self efficacy & $3.40 \pm 0.45$ & 0.33 & 1.02 & .90 & .85 & .68 \\
\hline Confidence & $3.37 \pm 0.70$ & -0.09 & -0.40 & .84 & & \\
\hline Self-regulated efficacy & $3.67 \pm 0.44$ & 0.25 & 1.30 & .86 & & \\
\hline Task difficulty & $2.81 \pm 0.67$ & 0.19 & -0.57 & .82 & & \\
\hline Problem solving ability & $3.68 \pm 0.43$ & 0.29 & 0.80 & .93 & .97 & .66 \\
\hline Clarifying problem & $3.76 \pm 0.48$ & -0.06 & 0.32 & .79 & & \\
\hline Seeking a solution & $3.71 \pm 0.48$ & 0.17 & 0.34 & .78 & & \\
\hline Decision making & $3.63 \pm 0.55$ & -0.07 & 0.37 & .81 & & \\
\hline Applying the solution & $3.68 \pm 0.49$ & 0.37 & 0.50 & .76 & & \\
\hline Evaluation & $3.61 \pm 0.52$ & -0.23 & 1.29 & .82 & & \\
\hline Clinical performance & $3.67 \pm 0.47$ & -0.17 & 0.71 & .91 & .95 & .67 \\
\hline Nursing process & $3.75 \pm 0.52$ & -0.38 & 1.24 & .80 & & \\
\hline Nursing intervention & $3.47 \pm 0.58$ & -0.11 & -0.04 & .65 & & \\
\hline Psychosocial nursing & $3.68 \pm 0.65$ & 0.40 & 0.24 & .80 & & \\
\hline Teaching & $3.73 \pm 0.62$ & -0.23 & -0.04 & .74 & & \\
\hline Physical examination and patient monitoring & $3.53 \pm 0.72$ & -0.40 & 0.38 & .74 & & \\
\hline Fundamental nursing & $3.86 \pm 0.58$ & -0.16 & 0.53 & .71 & & \\
\hline
\end{tabular}

$\mathrm{AVE}=$ average variance extracted; $\mathrm{CR}=$ construct reliability.

titutional Review Board (IRB) (no. 104549-140619-SB-003301), participants were recruited. Written consent was obtained, and small incentives, such as mugs, were offered. The survey was only administered to subjects who consented in writing to participate. The questionnaires included the following statement: "The subjects can withdraw his or her consent at any time; the data collected will be used for research only; the anonymity and confidentiality of all subjects will be guaranteed."

Data were collected through structured questionnaires from June 23 to September 11, 2014. A total of 220 questionnaires were distributed, and 205 (response rate: 93.2\%) were used in the final data analyses.

\section{Data Analysis}

SPSS/WIN 21.0 and AMOS 21.0 programs (IBM Corp.) were used for data analysis. The detailed data analysis method was as follows. First, descriptive statistics were used to analyze the general characteristics and measurement variables of participants, and the reliability of the study tools was analyzed using Cronbach's $\alpha$. Second, mean, variance, kurtosis, and skewness were obtained to test the normality test of the samples, and multi-collinearity was analyzed using Pearson's correlation coefficients. Third, for the structural equation model analysis, a measurement model was first verified, and then a structural model was verified. Confirmatory factor analysis was used to evaluate the validity of the latent variables in the measurement model. Fourth, the goodness of fit of the hypothetical model was verified using Goodness-of-Fit Index (GFI), Normed Fit Index (NFI), Comparative Fit Index (CFI), and Turker-Lewis Index (TLI). Fifth, Bootstrapping was performed to test the statistical significance of the total effect and indirect effects of the study model.

\section{RESULTS}

\section{Participants' Characteristics}

A total of 205 undergraduate nursing students participated, among them $92.2 \%$ were female, and the mean age was $23.07 \pm 1.35$ years. In terms of satisfaction with their major, the "satisfied" group accounted for $57.6 \%$ and the "moderate" group accounted for 39.0\%. For satisfaction with clinical practice, the "satisfied" group accounted for $49.8 \%$ and the "moderate" group accounted for $47.3 \%$. Regarding clinical practice stress, the "middle" group accounted for $66.8 \%$ and the "high" group accounted for $22.4 \%$. In terms of their relationships with peer groups in the clinical practice, the "good" group accounted for $84.4 \%$, and the "moderate" group accounted for $10.7 \%$ (Table 2). 


\section{Descriptive Statistics and Configuration Concepts of the Measurement Variables}

The results for the descriptive statistics (means, standard deviations) of the variables were as follows: emotional intelligence $5.18 \pm 0.71$; self efficacy $3.40 \pm 0.45$; problem solving ability $3.68 \pm 0.43$; and clinical performance $3.67 \pm$ 0.47 . Skewness and kurtosis were examined to check whether the variables had a normal distribution. The skewness value of all variables was 3.0 or less, and the kurtosis value was 10.0 or less (Table 1) [35].

Table 2. Participants' Demographic Characteristics $(N=205)$

\begin{tabular}{llc}
\hline Characteristics & Categories & $\mathrm{n}(\%)$ or M \pm SD \\
\hline Gender & Men & $16(7.8)$ \\
& Women & $189(92.2)$ \\
Age (year) & & $23.07 \pm 1.35$ \\
& $21 \sim 22$ & $50(24.4)$ \\
& $23 \sim 24$ & $128(62.4)$ \\
Satisfaction with & $25 \sim 30$ & $21(10.2)$ \\
nursing as a major & Dissatisfied & $7(3.4)$ \\
& Moderate & $80(39.0)$ \\
Satisfaction with & Satisfied & $118(57.6)$ \\
clinical practice & Dissatisfied & $6(2.9)$ \\
& Moderate & $97(47.3)$ \\
Clinical practice stress & Satisfied & $102(49.8)$ \\
& High & $46(22.4)$ \\
& Middle & $137(66.8)$ \\
Relationship with peer & Low & $22(10.7)$ \\
groups in the clinical & Bad & $4(2.0)$ \\
practice & Moderate & $22(10.7)$ \\
\hline & Good & $173(84.4)$ \\
\hline
\end{tabular}

\section{Hypothetical Model Verification}

Confirmatory factor analysis was conducted and a structural model was tested to verify the relationships among the subscales of emotional intelligence, self efficacy, problem solving ability, and clinical performance. As shown in Table 1, Average Variance Extracted (AVE) was higher than 0.5 , and Construct Reliability (CR) was higher than 0.7 for each factor. The emotional intelligence index was $.45(\mathrm{CR}=.77)$, self efficacy was $.68(\mathrm{CR}=.85)$, problem solving ability was $.66(\mathrm{CR}=.97)$, and clinical performance was $.67(\mathrm{CR}=.95)$. Although the AVE value of emotional intelligence was .45 , which was somewhat lower than the reference value, the reliability was higher than the reference value, and the reliability of the concept was 0.7 or higher. This was used for analysis as it was since there was no problem with convergent validity (Table 2). Further, goodness of fit in the hypothesized model was shown to be $x^{2}=183.186(\mathrm{dF}=118)$, GFI=.91, NFI=.91, CFI=.96, and Root Mean Squared Error of Approximation (RMSEA) was .05. This means that, in terms of the measurement model's goodness of fit, all indices met the conventional standards [36].

This study examined the direct effects, indirect effects, and total effects of exogenous variables such as one's own emotions, others' emotions, emotion utilization and emotion control on clinical performance, which is the final variable, through intervening variables such as self efficacy and problem solving ability. Bootstrapping was used to verify the significance of the indirect effects, and the results are shown in Table 3.

The variables that directly affected clinical performance

Table 3. Effects of Variables in Structural Equation Model

$(N=205)$

\begin{tabular}{|c|c|c|c|c|}
\hline Endogeneous variables & Exogeneous variables & Direct effect $(p)$ & Indirect effect $(p)$ & Total effect $(p)$ \\
\hline Clinical performance & $\begin{array}{l}\text { Problem solving ability } \\
\text { Self efficacy } \\
\text { Self-emotional appraisal } \\
\text { Others' emotional appraisal } \\
\text { Use of emotion } \\
\text { Regulation of emotion }\end{array}$ & $\begin{array}{l}.42(.007) \\
.29(.033) \\
.07(.357) \\
-.14(.106) \\
-.00(.902) \\
-.06(.453)\end{array}$ & $\begin{array}{l}.24 \quad- \\
.04(.005) \\
.20(.340) \\
.23(.005) \\
.15(.003) \\
(.003)\end{array}$ & $\begin{array}{l}.42(.007) \\
.54(.002) \\
.11(.182) \\
.06(.433) \\
.23(.005) \\
.09(.291)\end{array}$ \\
\hline Problem solving ability & $\begin{array}{l}\text { Self efficacy } \\
\text { Self-emotional appraisal } \\
\text { Others' emotional appraisal } \\
\text { Use of emotion } \\
\text { Regulation of emotion }\end{array}$ & $\begin{array}{r}.58(.005) \\
-.02(.779) \\
.25(.003) \\
.03(.673) \\
.09(.217)\end{array}$ & $\begin{array}{l}.05- \\
.11(.230) \\
.23(.008) \\
.13(.003) \\
\quad(.007)\end{array}$ & $\begin{array}{l}.58(.005) \\
.03(.605) \\
.35(.003) \\
.27(.005) \\
.22(.005)\end{array}$ \\
\hline Self efficacy & $\begin{array}{l}\text { Self-emotional appraisal } \\
\text { Others' emotional appraisal } \\
\text { Use of emotion } \\
\text { Regulation of emotion }\end{array}$ & $\begin{array}{l}.09(.237) \\
.19(.010) \\
.41(.004) \\
.22(.008)\end{array}$ & $\begin{array}{l}- \\
- \\
-\end{array}$ & $\begin{array}{l}.09(.237) \\
.19(.010) \\
.41(.004) \\
.22(.008)\end{array}$ \\
\hline
\end{tabular}




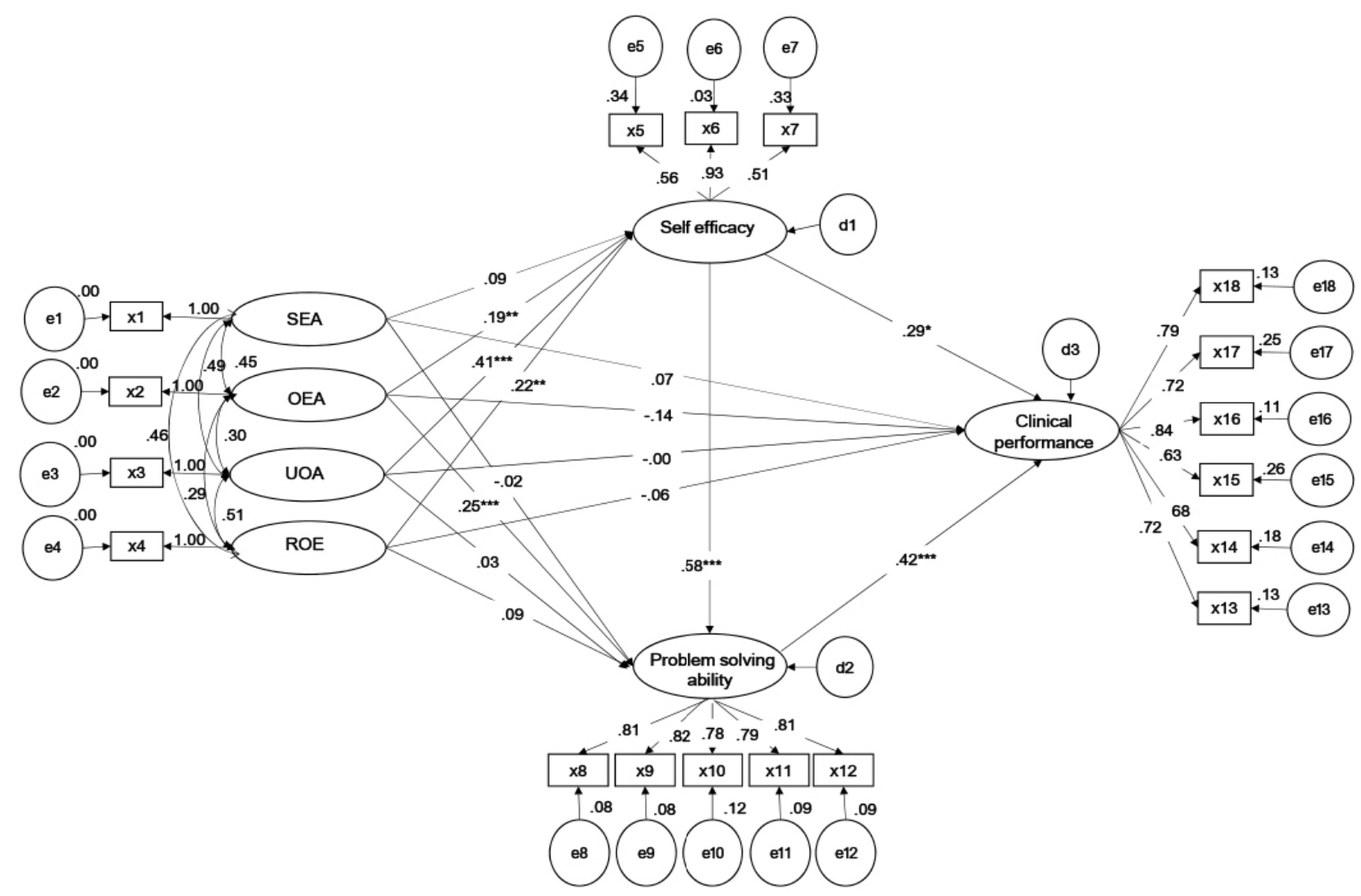

$\mathrm{SEA}=$ self-emotional appraisal; $\mathrm{OEA}=$ others' emotional appraisal; $\mathrm{UOE}=$ use of emotion; $\mathrm{ROE}=$ regulation of emotion. ${ }^{*} p<.050,{ }^{* *} p<.005,{ }^{* * *} p<.001$.

Figure 2. Path diagram of the final model.

were problem solving ability $(\beta=.42, p=.007)$ and self efficacy $(\beta=.29, p=.033)$. The variables that directly affected problem solving ability were self efficacy $(\beta=.58, p=.005)$ and others' emotional appraisal $(\beta=.25, p=.003)$. The variables that directly affected self efficacy were others' emotional appraisal $(\beta=.19, p=.010)$, use of emotion $(\beta=.41$, $p=.004)$, and regulation of emotion $(\beta=.22, p=.008)$. Also, exogenous variables such as others' emotional appraisal, use of emotion, and regulation of emotion all affected clinical performance indirectly $(p<.05)$ through intervening variables such as self efficacy and problem solving ability. Self-emotional appraisal did not affect clinical performance, either directly or indirectly (Figure 2).

\section{DISCUSSION}

This study aimed to build and test a model for the factors affecting nursing students' clinical performance based on Bandura's self efficacy theory and a literature review. The variables that most affected nursing students' clinical performance were found to be problem solving ability fol- lowed by self efficacy. Others' emotional appraisal, regulation of emotion, and use of emotion affected clinical performance indirectly. Furthermore, self efficacy was a significant mediating factor in the relationship between the sub-categories of emotional intelligence and clinical performance, supporting Bandura's self efficacy theory.

The results showed that problem solving ability had a direct effect on nursing students' clinical performance. Problem solving ability contributes to the effective resolution of various problems faced in the nursing field, so it has been recognized as a core performance skill that nurses should possess [17]. Previous studies have found that nursing students' problem solving ability was a major factor affecting clinical performance among nursing students [27]. Problem solving ability is a cognitive strategy acquired over a long period of time [27]. As such, it can be acquired through the repeated application of problem-based learning and evidence-based practice throughout the nursing curriculum.

Self efficacy has a direct effect on clinical performance. As it increases, clinical performance increases and high 
quality of nursing is more effectively provided to patients $[37,38]$. According to Bandura [18], high self efficacy helps students to succeed in their studies and practice, and the present findings support that. This study's results suggest that self efficacy acts as a driving force enabling nursing students to perform a given role effectively and as a major factor in increasing their clinical performance. Moreover, self efficacy has a mediating effect between the subcategories of emotional intelligence and clinical performance. This can also be seen as supporting Bandura's self efficacy theory. Self efficacy also plays a role in deriving positive effects from nursing education [39]. Therefore, when educators design clinical practice experiences for nursing students, it is advisable to take self efficacy theory into account.

Others' emotional appraisal, regulation of emotion, and use of emotion affect clinical performance indirectly through self efficacy and problem solving ability. This means that high emotional intelligence among nursing students increases their self efficacy and problem solving ability, and high self efficacy and problem solving ability enhance clinical performance, which improves nursing quality. Previous studies have suggested that emotional intelligence is a positive significant factor in clinical performance $[10,11]$. Others' emotional appraisal, regulation of emotion, and use of emotion have significant indirect effects through self efficacy; however, self-emotion does not. This also aligns with previous studies [10,40]. The present results suggest that a person with high emotional intelligence is good at motivation and utilizing emotion, which positively affect self efficacy - that is, the ability to work with confidence in any situation. For that reason, some studies have analyzed the effects emotional intelligence subscales on clinical performance $[7,12,13]$. Those studies indicated that while emotional intelligence has a static correlation with students' clinical performance and acts to influence it, each of its subcategories has a different level of effect on clinical performance. Therefore, to strengthen clinical performance, it is necessary to systematically analyze the subcategories of emotional intelligence and apply them to the curriculum.

Studies have found that a significant positive correlation exists between nursing students' self efficacy and their problem solving abilities, and that self efficacy influences problem solving ability [41]; this is consistent with the present findings. The results of prior study indicate that high emotional intelligence in nursing students raises their self efficacy and that high self efficacy improves clinical performance, which affects nursing quality by enhancing nurses' problem solving abilities. According to the present findings, only others' emotional appraisal affects problem solving ability both directly and indirectly. A person with high emotional intelligence can view problems from various perspectives and solve problems effectively [42]. According to one previous study, preservice teachers' emotional intelligence has a direct effect on problem solving ability [43]. The current study found that among the subcategories, only others' emotional appraisal had a direct effect on problem solving. No prior study has addressed the relationships between the subcategories of emotional intelligence and problem solving ability. As such, there is a need for further research in this area.

The present study suggests that others' emotional appraisal has a direct effect on problem solving ability and self-efficacy, and that the use of emotion and regulation of emotion both have direct effects on self efficacy. Based on these results, others' emotional appraisal should be considered in developing the emotional intelligence of nursing students. Since nurses need to maintain good therapeutic relationships with their patients, their emotional intelligence is a key factor in patient safety and clinical performance. Therefore, it is necessary to create an educational environment in nursing education that considers and develops students' emotional intelligence. Further, emotional intelligence should be considered and applied when developing nursing curricula and extracurricular programs to increase nursing students' self efficacy and problem solving abilities and thereby improve their clinical performance.

This study has some limitations. First, it used self-reported questionnaires that relied on the respondents. Thus, future research should use various measurement method to further validate the findings. Second, the participants were recruited from four colleges in two cities in Korea, which might have caused a setting bias. Therefore, the findings are not readily generalizable to all nursing students.

\section{CONCLUSION}

Based on Bandura's self efficacy theory framework and a literature review, this study established a predictive model for clinical performance among nursing students. The hypothesized model showed goodness of fit to the data.

This study clarified the direct and indirect effects of each variable, considering the emotional intelligence subcategories that affect self efficacy and positive interpersonal relationships and have statistically significant effects on nursing students' clinical performance. The major factors affecting clinical performance were problem solving ability and self efficacy. 
Based on this study's results, when developing nursing education programs, educators should consider a comprehensive approach that includes individual factors, self efficacy as a mediator, and skills for enhancing clinical performance.

\section{CONFLICTS OF INTEREST}

The authors declared no conflict of interest.

\section{AUTHORSHIP}

Study conception and design acquisition - KMS and SSK; Data collection - KMS; Analysis and interpretation of the data - KMS; Drafting and critical revision of the manuscript - KMS and SSK.

\section{ACKNOWLEDGEMENT}

This article is a revision of the first author's doctoral dissertation from Kosin University.

\section{REFERENCES}

1. Kahya E, Oral N. Measurement of clinical nurse performance: developing a tool including contextual items. Journal of Nursing Education and Practice. 2018;8(6):112-23.

https://doi.org/10.5430/jnep.v8n6p112

2. Park JW, Kim C-J, Kim YS, Yoo MS, Yoo HR, Chae S-M, et al. Impact of critical thinking disposition, general self-efficacy, and leadership on clinical competence in nursing students. Korean Journal Medical Education. 2012:24(3):223-31. https://doi.org/10.3946/kjme.2012.24.3.223

3. Nabolsi M, Zumot A, Wardam L, Abu-Moghli F. The experience of Jordanian nursing students in their clinical practice. Procedia - Social and Behavioral Sciences. 2012;46:5849-57. https://doi.org/10.1016/j.sbspro.2012.06.527

4. Hickey MT. Preceptor perceptions of new graduate nurse readiness for practice. Journal for Nurses in Staff Development. 2009;25(1):35-41.

https://doi.org/10.1097/NND.0b013e318194b5bb

5. Baraz S, Memarian R, Vanaki Z. Learning challenges of nursing students in clinical environments: a qualitative study in Iran. Journal of Education and Health Promotion. 2015;4(52). https://doi.org/10.4103/2277-9531.162345

6. Hartigan-Rogers JA, Cobbett SL, Amirault MA, Muise-Davis ME. Nursing graduates' perceptions of their undergraduate clinical placement. International Journal of Nursing Education Scholarship. 2007;4(1).

https://doi.org/10.2202/1548-923X.1276

7. Bakr MM, Safaan SM. Emotional intelligence: a key for nurses' performance. The Journal of American Science. 2012;8(11): 385-93. https://doi.org/10.7537/marsjas081112.59

8. Codier E, Codier D. Do emergency nurses have enough emo- tional intelligence? Emergency Nurse. 2015;23(3):26-9. https://doi.org/10.7748/en.23.3.26.e1388

9. Codier E, Codier D. A model for the role of emotional intelligence in patient safety. Asia-Pacific Journal of Oncology Nursing. 2015;2(2):112-7. https://doi.org/10.4103/2347-5625.157594

10. Kim MS. The mediating effect of self-efficacy in the relationship between emotional intelligence and clinical performance among nursing students. The Journal of Korean Academic Society of Nursing Education. 2016;22(4):504-13.

https://doi.org/10.5977/jkasne.2016.22.4.504

11. Yang S-Y. The effect of emotional intelligence and self-efficacy on clinical competence of the nursing students. The Journal of the Korea Contents Association. 2015;15(6):370-8.

https://doi.org/10.5392/JKCA.2015.15.06.370

12. Andonian L. Emotional intelligence, self-efficacy, and occupational therapy students' fieldwork performance. Occupational Therapy In Health Care. 2013;27(3):201-15. https://doi.org/10.3109/07380577.2012.763199

13. Beauvais AM, Brady N, O'Shea ER, Griffin MTQ. Emotional intelligence and nursing performance among nursing students. Nurse Education Today. 2011;31(4):396-401. https://doi.org/10.1016/j.nedt.2010.07.013

14. Chaung SK. Critical thinking disposition, problem solving ability, and clinical competence in nursing students. Journal of Korean Academy of Fundamentals of Nursing. 2011;18(1): 71-8.

15. Altun, I. The perceived problem solving ability and values of student nurses and midwives. Nurse Education Today. 2003; 23(8):575-84. https://doi.org/10.1016/S0260-6917(03)00096-0

16. Kim K-S, Choi J-H. The relationship between problem solving ability, professional self concept, and critical thinking disposition of nursing students. International Journal of BioTechnology. 2014;6(5):131-42.

https://doi.org/10.14257/ijbsbt.2014.6.5.13

17. Lee E-J, Yi Y-J, Kim Y-S, Jo H-S, Kim H-S, KIM Y-M, et al. Comparison of factors affecting clinical competence between associate and bachelor nursing students completed nursing courses. The Journal of Korean Academic Society of Nursing Education. 2011;17(2):218-25. https://doi.org/10.5977/JKASNE.2011.17.2.218

18. Bandura A. Self-efficacy: toward a unifying theory of behavioral change. Psychological Review. 1977;84(2):191-215. https://doi.org/10.1037/0033-295X.84.2.191

19. Park M. Gender difference in mediating effects of self-efficacy for the prevention of sexually transmitted disease (STD) among college students' STD knowledge, susceptibility, and sexual autonomy. Korean Journal of Adult Nursing. 2016;28(4):482-90. https://doi.org/10.7475/kjan.2016.28.4.482

20. Kim H-J, Lee MK. The relationship between illness perception 
and health behaviors among patients with tuberculosis: mediating effects of self-efficacy and family support. Korean Journal of Adult Nursing. 2017;29(6):626-36.

https:// doi.org/10.7475/kjan.2017.29.6.626

21. Bandura A. Self-efficacy: the exercise of control. Park YS, Kim YC, translator. Seoul: Kyoyook-kwahak-sa Co; 2001.

22. Maddux JE, Snyder CR, Lopez SJ. editors. Self-efficacy: the power of believing you can. NY: Oxford University Press; 2000.

23. Zimmerman BJ. Self-efficacy: an essential motive to learn. Contemporary Educational Psychology. 2000;25(1):82-91. https://doi.org/10.1006/ceps.1999.1016

24. Por J, Barriball L, Fitzpatrick J, Roberts J. Emotional intelligence: its relationship to stress, coping, well-being and professional performance in nursing students. Nurse Education Today. 2011;31(8):855-86. https://doi.org/10.1016/j.nedt.2010.12.023

25. Zengin N, Pinar R, Akinci AC, Yildiz H. Psychometric properties of the self-efficacy for clinical evaluation scale in Turkish nursing students. Journal of Clinical Nursing. 2013;23(7-8): 976-84. https://doi.org/10.1111/jocn.12257

26. Rice E. Predictors of successful clinical performance in associate degree nursing students. Nurse Educator. 2015;40(4): 207-11. https:// doi.org/10.1097/NNE.0000000000000136

27. Park H-S, Han J-Y. Factors influencing clinical competence in nursing students. Journal of Korean Academy of Fundamentals of Nursing. 2013;20(4):438-48.

https://doi.org/10.7739/jkafn.2013.20.4.438

28. Wong C-S, Law KS. The effects of leader and follower emotional intelligence on performance and attitude: an exploratory study. The Leadership Quarterly. 2002;13(3):243-74. https://doi.org/10.1016/S1048-9843(02)00099-1

29. Jung HY. An empirical study on the effect of emotional intelligence on organizational effectiveness [dissertation]. Busan: Pusan National University; 2007.

30. Lee WS, Park SH, Choi EY. Development of a Korean problem solving process inventory for adults. Journal of Korean Academy of Fundamentals of Nursing. 2008;15(4):548-57.

31. Cha J-E. A study for the general self-efficacy scale development [master's thesis]. Seoul: Ewha Womans University; 1997.

32. Kim A. A study on the academic failure-tolerance and its correlates. The Korean Journal of Educational Psychology. 1997;
11(2):1-19.

33. Lee WH, Kim C, Yoo JS, Hur HK, Kim KS, Lim SM. Development of a clinical competency measurement tool for student. Yonsei Nursing. 1990;13:17-45.

34. Yang J-J, Park M-Y. The relationship of clinical competency and self-directed learning in nursing students. The Journal of Korean Academic Society of Nursing Education. 2004;10(2): 271-7.

35. Kim KS. AMOS Structural equation model analysis. Seoul: Hannare Publishing Co.; 2010. p. 184-454.

36. Woo JP. Structural equation modeling concept. Seoul: Hannare Publishing Co.; 2012. p. 328-91.

37. Fillion L, Fortier M, Goupil RL. Educational needs of palliative care nurses in Quebec. Journal of Palliative Care. 2005;21(1): 12-8.

38. Kuiper RA, Murdock N, Grant N. Thinking strategies of baccalaureate nursing students prompted by self-regulated learning strategies. Journal of Nursing Education. 2010;49(8):42936. https://doi.org/10.3928/01484834-20100430-01

39. Karabacak Ü, Sebest S, Öntürk ZK, Aslan FE, Olgun N. Relationship between student nurses' self-efficacy and psychomotor skills competence. International Journal of Nursing Practice. 2013;19(2):124-30. https://doi.org/10.1111/ijn.12051

40. Gharetepeh A, Safari Y, Pashaei T, Razaei M, Baqher Kajbaf M. Emotional intelligence as a predictor of self-efficacy among students with different levels of academic achievement at Kermanshah University of Medical Sciences. Journal of Advances in Medical Education and Professionalism. 2015;3(2):50-5.

41. Sim M-J, Oh H-S. Influence of self efficacy, learning motivation, and self-directed learning on problem-solving ability in nursing students. The Journal of the Korea Contents Association. 2012;12(6):328-37. https://doi.org/10.5392/JKCA.2012.12.06.328

42. Libbrecht N, Lievens F, Carette B, CôtéS. Emotional intelligence predicts success in medical school. Emotion. 2014;14(1):64-73. https://doi.org/10.1037/a0034392

43. Deniz S. The relationship between emotional intelligence and problem solving skills in prospective teachers. Educational Research and Reviews. 2013;8(24):2339-45. 